\title{
All Keynesians now? \\ Public support for countercyclical government borrowing
}

\author{
Lucy Barnes \\ School of Public Policy, \\ University College London \\ 1.barnes@ucl.ac.uk \\ ucl .academia.edu/LucyBarnes
}

\author{
Timothy Hicks \\ School of Public Policy, \\ University College London \\ t.hicks@ucl.ac.uk \\ tim.hicks.me.uk/
}

This version: October 9, 2018*

${ }^{*}$ We are grateful for feedback on versions of this project to: Thomas Sattler, and audiences at The Hertie School of Governance "Political Economy" seminar and the University of Washington Severyns Ravenholt seminar in Comparative Politics. 


\title{
All Keynesians now? \\ Public support for countercyclical government borrowing
}

Word count: $\approx 3,950$

\begin{abstract}
In the wake of the 2008 financial crisis, macroeconomic policy returned to the political agenda, and the influence of Keynesian ideas about fiscal stimulus rose (and then fell) in expert circles. Much less is known, however, about whether and when Keynesian prescriptions for countercyclical spending have any support among the general public. We use a survey experiment, fielded twice, to recover the extent to which UK respondents hold such countercyclical attitudes. Our results indicate that public opinion was countercyclical - Keynesian - in 2016. We then use Eurobarometer data to estimate the same basic parameter for the population for the period 2010-2017. The observational results validate our experimental findings for the later period, but also provide evidence that the UK population held procyclical views at the start of the period. Thus, there appear to be important dynamics in public opinion on a key macroeconomic policy issue.
\end{abstract}




\section{Introduction}

In the aftermath of the financial crisis, fiscal policy became a central economic policy concern. Policymakers adopted Keynesian stimulus packages to avert recession, and then faced high levels of public debt as the cost of bank bailouts passed through to government balance sheets. The resurgence of Keynesian ideas in 2008 and the subsequent turn to austerity have redirected scholarly attention to the economic ideas held by economists and policy-makers (Blyth 2013; Farrell and Quiggin 2017). A central theme in these discussions has been the appropriate response of government borrowing to the level of economic performance, with the Keynesian, countercyclical position being that consolidation when the economy is weak in inadvisable (and even counterproductive). But these changes in elite ideas have happened in the context of electoral pressures privileging economic performance (Bartels 2013), with government borrowing firmly on the public agenda. We seek to contribute to this debate by providing - as far as we know - the first explicit attempt to document the degree to which voters' views on government borrowing change with economic conditions. Specifically, we are interested in whether British voters prefer higher borrowing in economic bad times - which we call 'Keynesian' policy.

In general, variation in economic performance is not easily separable from other economic and political differences, so our core approach is experimental. To elicit the responsiveness of views on the deficit to economic conditions, we manipulate perceptions of macroeconomic performance. Survey respondents in the UK in 2016 behaved in a Keynesian way: those who saw a positive report about the economy were more deficit averse, on average, than those who receive a more negative view.

We extend this finding using observational evidence to describe temporal variation in the link between economic performance and support for borrowing, and to anchor our experimental results in external context. Using Eurobarometer data, we find that from 2015 onwards, people who thought the national economy was doing less well were more supportive (or accepting) of deficits than those who thought it was doing well. This is in line with our experimental evidence. Before 2013, however, there was a negative relationship between perceptions of the national economy and aversion to deficits: preferences among the British electorate appeared to be procyclical.

These results make two important contributions to our understanding of the political economy of fiscal policy. First, while we would not want to overstate claims about the macroeconomic reasoning of our respondents, our results provide important nuance to claims about voter reactions to stimulus and consolidation which tend to stress systematic voter dislike of consolidation (e.g. Hübscher and Sattler 2017). They provide equal qualification to opposing accounts stressing the surprising popularity of austerity policies since the financial crisis (Barnes and Hicks 2018). Instead, voters' views on austerity may depend on the situation. The second important aspect of our results is that the degree of Keynesianism in public attitudes is not static. British voters have changeable - perhaps even malleable - attitudes over what constitutes a defining feature of modern macroeconomics. This finding opens up new terrain for work at the intersection of political economy and political behaviour. 


\section{Theoretical Priors}

Our starting point is to note that textbook Keynesian models yield policy prescriptions of countercyclical government spending: when the economy performs worse, governments should increase expenditure to sustain aggregate demand (e.g. Carlin and Soskice 2006). Countercyclicality is generally accepted as a core feature of Keynesian intellectual approaches. Amongst political scientists, attention has centered on whether this kind of countercyclical policy garners support at the elite level (Blyth 2013; Farrell and Quiggin 2017). While mass attitudes form the background to some of these accounts, the prevalence of Keynesian attitudes (or not) among voters has largely been left unstudied.

There is, however, a literature studying mass attitudes towards government borrowing. Much of this has been concerned with whether voters are "fiscal conservatives" or not (e.g. Barnes and Hicks 2018; Bisgaard and Slothuus 2018; Blinder and Holtz-Eakin 1983; A. Modigliani and F. Modigliani 1987; Peltzman 1992). There is also work on the electoral costs of deficits and budgetary consolidation, with somewhat mixed findings (e.g. Alesina, Carloni, and Lecce 2013; Brender and Drazen 2008; Hübscher and Sattler 2017). This work teaches us about voter preferences over stimulus versus consolidation, but not on cyclicality - how these preferences are linked to macroeconomic performance - which is our focus here.

One strand of the political science literature that implicitly speaks to this issue is the "policy mood" approach. Work in this area has highlighted that better economic performance tends to shift public opinion to the left, while economic contraction moves the public to the right (Stevenson 2001). On this view, voters want to "buy" more government intervention when they have higher incomes (Durr 1993). From this intuition we might suspect that mass attitudes will be procyclical: just at those times when government activism is needed (in recessions), public support for it will dissipate.

Thus, the existing literature gives mixed guidance on what to expect of mass attitudes regarding macroeconomic cyclicality and public deficits. Keynesian macroeconomists endorse countercyclical policy. Scholars of the politics of ideas describe the intellectual ascendance of Keynesianism at the nadir of the financial crisis, followed by its rapid demise. Meanwhile, policy mood scholars would seem to indicate that we should expect procyclical mass attitudes.

This raises the question: is public opinion on deficits countercyclical (Keynesian), procyclical, or neither? Put another way: when the economy is doing better (worse) are voters more (less) likely to favour deficit reduction?

\section{The Survey Experiment}

The ideal way to investigate this question would be to observe individuals' views on austerity when they are faced with exogenous differences in economic growth, but such exogenous objective variation is near-impossible to find. However, since our concern is with attitudes at the individual level, we can leverage differences in individuals' perceptions of economic performance where there is more variation, and where we can ensure that (some) variation is exogenous. We did exactly this in two rounds of a survey experiment, fielded in the UK in March and July of 2016.

Respondents in our experiment were randomly assigned to an information treatment that presented the (then) recent performance of the British economy in either (a) an absolutely and relatively 
good light, or (b) an absolutely and relatively bad light. All respondents were then immediately asked a question capturing attitudes about the importance of deficit reduction.

One treatment group saw the figure and caption set out in figure 1a. The other group saw figure $1 \mathrm{~b}$ and its caption. The first treatment presented data on average annual wages in the UK compared to the mean for the rest of Europe and France, respectively. ${ }^{1}$ These are real data which imply that the performance of the UK economy (in this regard) was both absolutely and relatively poor for the period 2010-2014. The second treatment used data on GDP in the UK compared to the European average and France. In contrast to the first treatment, this figure implies that the British economy performed both absolutely and relatively well for the same period. Again, these are real data, so neither group was deceived. Below each figure, we presented a variant of the same text explaining the figure, where a small subset of the words were adjusted to reflect what the underlying data actually were, and whether the inference about economic performance in the UK is positive or negative.

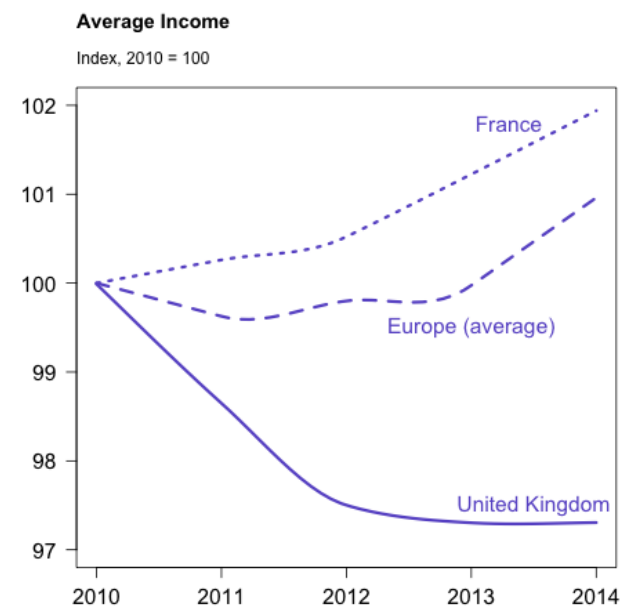

(a) "Income in the UK (as measured by average annual wages) is stagnating, and has fallen considerably over the past five years. As the figure shows, we are now around $3 \%$ worse off than we were in 2010. This performance is weak in comparison to other countries: the UK has done much worse than the European average, as well as other large economies like France."

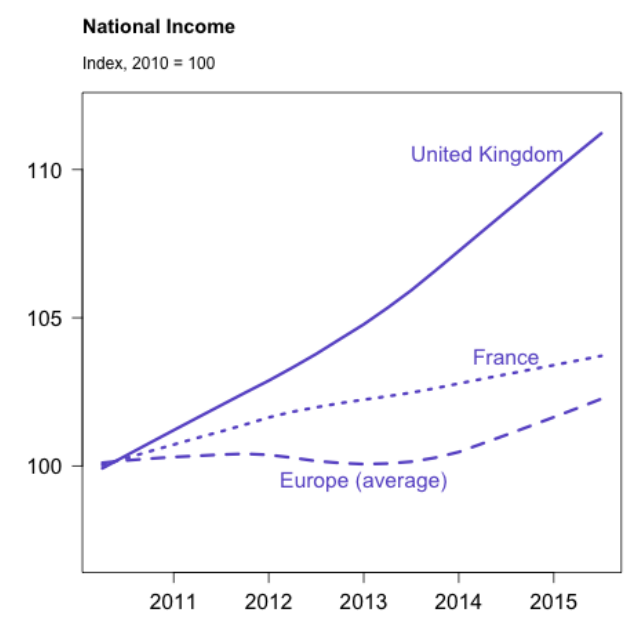

(b) "Income in the UK (as measured by national GDP) is at all time high levels, and has grown considerably over the past five years. As the figure shows, we are now around $11 \%$ better off than we were in 2010. This performance is strong in comparison to other countries: the UK has done much better than the European average as well as other large economies like France."

Figure 1: Figures and text for the two treatment conditions in each of the two survey experiments fielded.

We ran the experiment with no neutral, no-information control group, as the difference from a 'natural' baseline has no inferential power nor descriptive interest in terms of our question. Rather, we sought to maximise the distance on perceptions of macroeconomic performance between the two groups.

To measure attitudes about government borrowing, we replicated a question from the Eurobarometer surveys. Respondents were asked to indicate their level of (dis)agreement with the following statement: "Measures to reduce the public deficit and debt in the UK are not a priority for now".

\footnotetext{
${ }^{1}$ The international benchmarking aspect of the design follows the findings of Kayser and Peress (2012).
} 
Response options were: "Totally agree"; "Tend to agree"; "Tend to disagree"; "Totally disagree", and "Don't know".

The design and analysis for the experiments was not pre-registered, and we are happy to make clear that we anticipated finding procyclical policy preferences. Indeed, the reason we conducted two identical experiments was because we were surprised enough at the results from the first experiment that we feared there had either been some idiosyncratic mistake in its implementation. Experiment 1 (fielded on March 8th 2016) had a sample of around 1,700 and experiment 2 (June 30 - July 12016 ) had a sample of around 3,400.

Clearly, our experiment does not vary the actual performance of the economy, but rather the information our respondents have about economic performance. We are sanguine about this for two reasons. In general theoretical terms, people's perceptions of the economy provide the channel by which it should primarily influence their attitudes. Second, in Britain in 2015 to 2016, economic performance in reality was quite mixed - for example, with good performance on growth and employment, but rather worse outcomes on wages. This allows our information treatments to be credible, and to provide useful information for respondents to update their beliefs about performance.

In observational settings, how people evaluate the economy is strongly influenced by their partisan orientation towards the incumbent government (Evans and Pickup 2010), and those same partisan cues shape perceptions of the budget deficit (Bisgaard and Slothuus 2018); a topic where preferences for action are liable to influence by elite messages (Barnes and Hicks 2018). Disentangling how assessments of the economy and attitudes towards the deficit move together organically is therefore difficult. In contrast, while the information we present to respondents may be processed differently according to pre-existing views or partisan orientation, the assignment of good or bad news orthogonally to these party preferences means that our average treatment effect estimate is unaffected by these relationships.

\subsection{Results}

In this section we present our main results, based on pooling the data from both experiments. ${ }^{2}$ The estimates that we present here are based on ordinary least squares (OLS) models, with our dependent variable recoded to an interval variable ranging from 1 to 4 ; higher values correspond to more hostility to government borrowing. Results from ordered logit models are included in the supplementary material, but given their substantive similarity, we report the OLS results here for their easier interpretability. ${ }^{3}$

Figure 2 presents the core experimental finding. It shows a coefficient plot for two models: one with just the treatment dummy and the experiment dummy, and the other with additional controls for gross household income, newspaper readership, and 2015 general election vote. The top two points show the estimated coefficients for the 'good economy' treatment, as compared to the 'bad economy' treatment, in the two models. ${ }^{4}$ Each estimated coefficient is presented as a point estimate and $95 \%$ (darker bars) and 99\% (lighter bars) confidence interval. The core inference is clear: voters

\footnotetext{
${ }^{2}$ All models estimated on the combined sample include a dummy variable indicating the wave of each observation. The supplementary material (section A), provides the separate results for each experiment, showing that the findings are essentially the same when the samples are analysed separately.

${ }^{3}$ All results reported in this paper apply sample weights to make the sample representative of the UK population.

${ }^{4}$ The randomization appears to work well, in the sense that there is little movement in the estimated treatment effect once control variables are included.
} 
shown a more positive view of the UK economy express greater hostility for government debts and deficits. Their preferences over deficits are countercyclical. ${ }^{5}$

The remaining points in figure 2 show a selection of the other coefficients from the model including pre-treatment characteristics in order to provide some substantive context for the magnitude of our estimated treatment effect. (These estimates should not be interpreted causally as they are based on observational variation across respondents, rather than random assignment.) The effect of our treatment(s) is almost half the magnitude of the observed differences between Telegraph and Guardian readers, and those who report not reading a newspaper. Similarly, it is about one third of the magnitude of the Labour-Conservative voter difference.

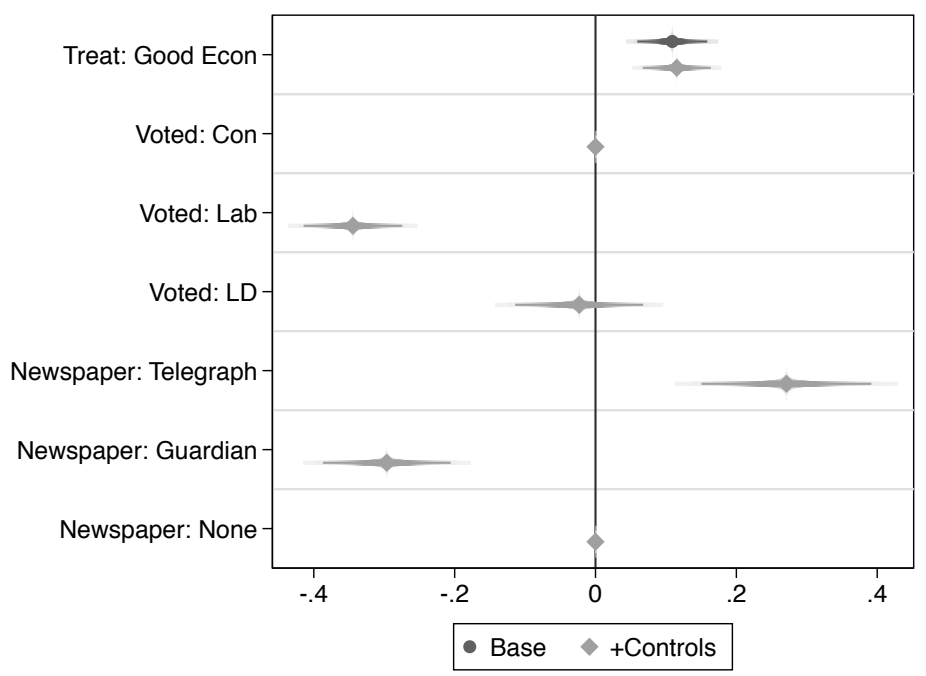

Figure 2: Coefficient plot showing estimates of causal effect of respondents seeing information presenting the UK economy as performing well, versus badly, on reported attitudes regarding the importance of deficit reduction. Positive values imply greater support for deficit reduction. 'Base' model has only the treatment dummy and a dummy for Experiment 1 versus Experiment 2. '+Controls' also includes factorial controls for: 2015 general election vote choice; newspaper readership, and; gross household income. Estimates are from OLS models (model 1 in each of tables A5 and A6 in the supplementary material). Darker (lighter) bars show $95 \%$ (99\%) confidence intervals.

\footnotetext{
${ }^{5}$ In the supplementary material (figure A3), we show that this on-average Keynesianism seems to be driven by left-identifying respondents.
} 


\section{Observational Extension: External Validity}

Our evidence so far indicates that, in a simple survey experiment, respondents react to economic news with countercyclical deficit preferences. But, like all experiments, these results are open to scepticism about the degree to which they reflect any broader, real phenomenon. To address some of these questions of external validity, we use observational survey data to benchmark our results against parallel measurements. We analyse data from the UK sub-sample of 16 waves of the Eurobarometer survey, fielded between 2010 and 2017, in which respondents are asked about both their assessment of national economic performance, and their preferences over national fiscal consolidation.

The Eurobarometer surveys ask half of respondents (with a random split) exactly the same question that we use in our experiment, seeking levels of agreement with the statement that "Measures to reduce the public deficit and debt in (OUR COUNTRY) are not a priority for now." The other half are asked for their level of agreement with a statement with the opposite valence: "Measures to reduce the public deficit and debt in (OUR COUNTRY) cannot be delayed." To make use of the full available sample, we combine responses to these two instruments - excluding "Don't know" responses - by reversing the scale of one question. Again this outcome measure takes a value of $1,2,3$, or 4 , and is scaled such that higher values correspond with more negative attitudes towards public borrowing. ${ }^{6}$

We are interested in the association between this measure and respondent perceptions of the macroeconomy. We measure the latter using responses to the question, "How would you judge the current situation in the (NATIONALITY) economy[?]". The available responses were: "Very good", "Rather good", "Rather bad", "Very bad", and "Don't know". We again construct a numeric variable ranging from 1 to 4 , where higher values correspond to more positive perceptions of the economic situation. ${ }^{7}$ Just as our experimental treatment effect captures the elasticity of deficit preferences to good or bad economic news, the association between these two variables captures the elasticity of deficit preferences to perceived economic performance.

Again, the use of the subjective economic perceptions here is worth comment. The main advantage is that it enables us to again see variation "in the macro-economy" at the individual level. The objective macroeconomy is clearly the same for all respondents (in any survey wave), and so provides limited variation. A reliance on subjective economic performance also mirrors our experiment, so holds further appeal in this specific application.

However, in the observational data, these assessments of the macroeconomy are not exogenously given, and the endogeneity may be problematic. For example, Conservative voters are more likely to have a greater level of support for fiscal consolidation, and given Conservative incumbency in office in the period in question, are also likely to have more favourable assessments of the economy (Evans and Pickup 2010). ${ }^{8}$ In section B.1 of the supplementary material, we show that the empirical evidence indicates that this does not drive our results. Nonetheless, the aim of this observationallybased analysis is less to recover a causal estimate than to describe the association in the broader data, and over time, beyond the confines of our experiment. As such, the main figures show simple associations. ${ }^{9}$

\footnotetext{
${ }^{6}$ In all models that we estimate using these combined responses, we include a dummy variable indicating which question wording was used.

${ }^{7}$ Excluding "Don't know" responses.

${ }^{8}$ But see De Vries, Hobolt, and Tilley (2018).

${ }^{9}$ Analogous results from models with some control variables can be found in section $\mathrm{B}$ in the supplementary
} 
What we are interested in, then, is the association between economic performance and support for budget consolidation. Where economic "good times" are associated with greater support for consolidation, the relationship between our two variables will be positive. This represents 'countercyclicality' in aggregate opinion. Figure 3 shows these associations wave-by-wave for the the eight year span of the data.

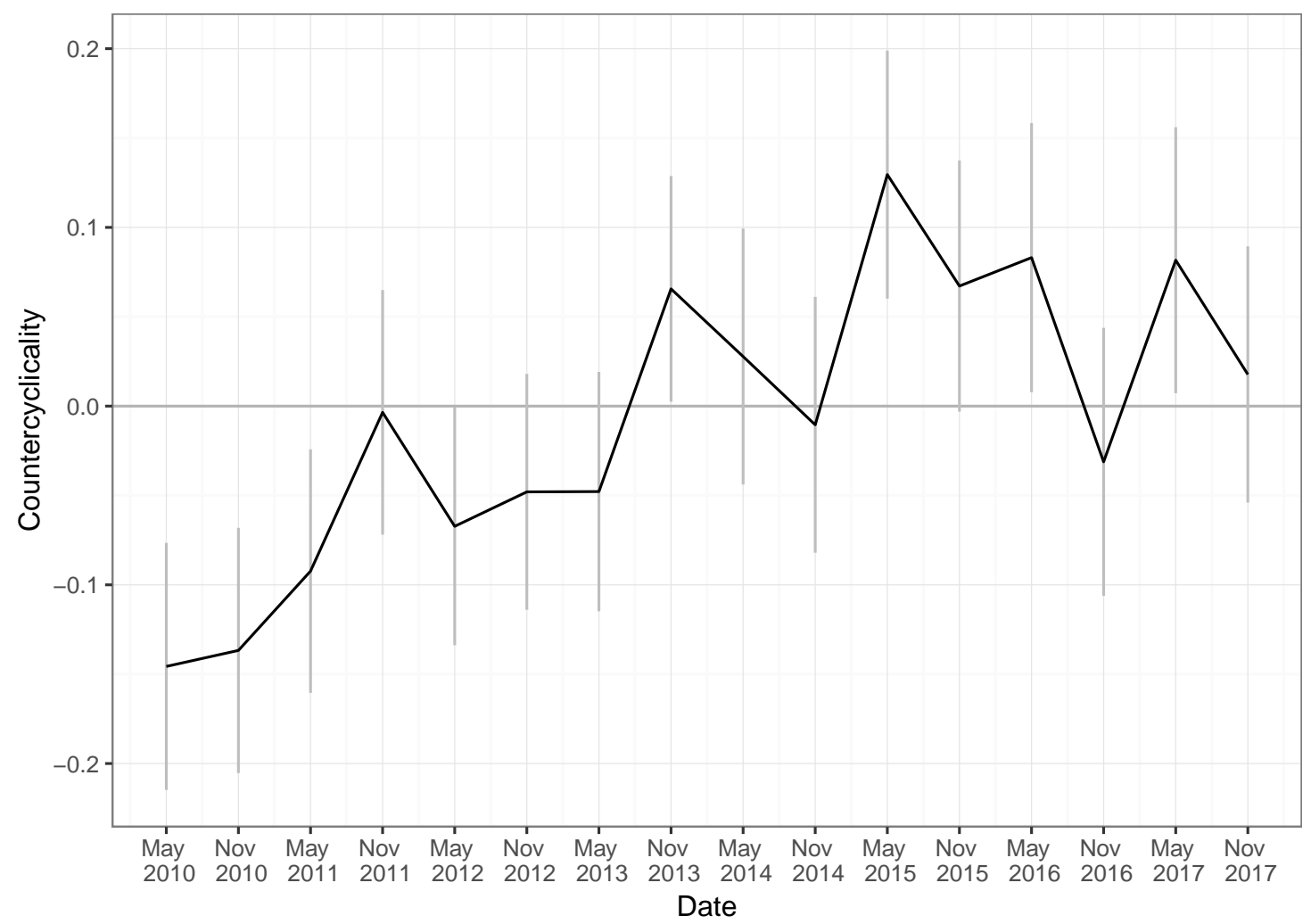

Figure 3: Estimated associations between support for deficit reduction and evaluation of economic performance. Positive values indicate more support for consolidation among those who think the economy is doing well (thus 'countercyclical', in the aggregate); negative values indicate more support for consolidation among those who think it is doing poorly.

The figure shows three important things. First, public attitudes in the UK since 2015 have been generally countercyclical, with the exception of the outlying data point for November $2016 .{ }^{10}$ Second, this countercyclicality has not always been the case, even over the short span of the past eight years. Opinion has become more countercyclical over time, and when the coalition government came to office (in May 2010) it was distinctly procyclical. We do not speculate as to whether as cause or consequence, but this pattern is consistent with the popularity of Osborne's austerity packages despite the context of global recession at that time.

Finally, figure 3 provides reassuring context for our survey experiment. Our two surveys bracket the May 2016 wave which recovers a statistically significant and positive association between economic assessment and support for consolidation. The coefficient from the observational data, 0.08, represents the difference in deficit preferences associated with a one-category move in macroeconomic materials.

${ }^{10}$ One explanation for the November 2016 deviation, which we unfortunately do not have the covariate data to explore, is that perceptions of the economy in this survey wave were distorted by the preceding Brexit campaign which took place over the summer of 2016. 
evaluation; our treatment effect (which, recall, is the difference between good and bad economic performance information) of 0.12 is readily comparable as the outcomes are on the same scale. It does not seem incredible that the presentation of extremely negative information on average wages, compared to the very positive GDP growth story, would correspond to an effect of this size. Here, then, the Eurobarometer data confirm that the countercyclical preferences that we elicit with our treatment have a reasonable parallel outside of the experimental context.

\section{Conclusion}

The findings in this paper speak to a range of ongoing debates in the political economy literature and in the real world of British politics. The finding that voters' preferences were procyclical in the period immediately after the 2010 general election is consistent with how political elites conceived of the issue at the time. For example, Labour's polling expert, James Morrison, noted in 2010 that "[a] Labour leader who argues that we should keep spending to secure growth is flying in the face of common sense" (quoted in Cowley and Kavanagh 2016, 72). Moreoever, the decline and reversal of this procyclical tendency in subsequent years is consistent with cross-national evidence to the effect that right-wing parties prospered immediately after both the Great Depression and the Great Recession, before left-wing parties returned to electoral strength (Lindvall 2014; Lindvall 2017). Our evidence is consistent with this electoral dynamic being related to underlying changes in attitudes about public policy.

This connection to cross-national evidence is suggestive of the wider contribution that this paper brings. The period of relative economic stability known as the Great Moderation led political economists to focus their attention on distributive issues within economies. Indeed, the Financial Crisis and Great Recession, if anything, provided greater rhetorical force to findings in this area. However, this distributive focus has diverted attention away from more traditional, and equally critical, agendas related to the political economy of macroeconomic management. ${ }^{11}$ Part of the contribution of this paper, then, is to connect contemporary political developments back to those earlier debates.

\section{References}

Alesina, Alberto, Dorian Carloni, and Giampaolo Lecce. 2013. "The Electoral Consequences of Large Fiscal Adjustments", in: Fiscal Policy after the Financial Crisis, ed. by Alberto Alesina and Francesco Giavazzi, University of Chicago Press: 531-570.

Barnes, Lucy and Timothy Hicks. 2018. "Making Austerity Popular: The Media and Mass Attitudes Towards Fiscal Policy", American Journal of Political Science 62(2): 340-354.

Bartels, Larry M. 2013. "Political Effects of the Great Recession", Annals of the American Academy of Political and Social Science 650(1): 47-76.

Bisgaard, Martin and Rune Slothuus. 2018. "Partisan Elites as Culprits? How Party Cues Shape Partisan Perceptual Gaps", American Journal of Political Science 62(2): 456-469.

Blinder, Alan S. and Douglas Holtz-Eakin. 1983. Public Opinion and the Balanced Budget, Working Paper 1234, National Bureau of Economic Research.

\footnotetext{
${ }^{11}$ Of which Hibbs (1977) is a classic example.
} 
Blyth, Mark. 2013. Austerity: The History of a Dangerous Idea, Oxford, UK: Oxford University Press.

Brender, Adi and Allan Drazen. 2008. "How Do Budget Deficits and Economic Growth Affect Reelection Prospects? Evidence from a Large Panel of Countries", American Economic Review 98(5): 2203-2220.

Carlin, Wendy and David Soskice. 2006. Macroeconomics: Imperfections, Institutions \& Policies, Oxford, UK: Oxford University Press.

Cowley, Philip and Dennis Kavanagh. 2016. The British General Election of 2015, Basingstoke, UK: Palgrave MacMillan.

De Vries, Catherine E., Sara B. Hobolt, and James Tilley. 2018. "Facing up to the facts: What causes economic perceptions?", Electoral Studies 51: 115-122.

Durr, Robert H. 1993. "What Moves Policy Sentiment?", American Political Science Review 87(1): $158-170$.

Evans, Geoffrey and Mark Pickup. 2010. "Reversing the Causal Arrow: The Political Conditioning of Economic Perceptions in the 2000-2004 U.S. Presidential Election Cycle", Journal of Politics 72 (4): $1236-1251$.

Farrell, Henry and John Quiggin. 2017. "Consensus, Dissensus, and Economic Ideas: Economic Crisis and the Rise and Fall of Keynesianism", International Studies Quarterly 61(2): 269-283.

Hibbs, Douglas A. 1977. "Political Parties and Macroeconomic Policy", American Political Science Review 71(4): 1467-1487.

Hübscher, Evelyne and Thomas Sattler. 2017. "Fiscal Consolidation Under Electoral Risk", European Journal of Political Research 56(1): 151-168.

Kayser, Mark Andreas and Michael Peress. 2012. "Benchmarking across Borders: Electoral Accountability and the Necessity of Comparison", American Political Science Review 106(3): 661-684.

Lindvall, Johannes. 2014. "The Electoral Consequences of Two Great Crises", European Journal of Political Research 53(4): 747-765.

- . 2017. "Economic Downturns and Political Competition since the 1870s", Journal of Politics 79(4): 1302-1314.

Modigliani, Andre and Franco Modigliani. 1987. "The Growth of the Federal Deficit and the Role of Public Attitudes", Public Opinion Quarterly 51(4): 459-480.

Peltzman, Sam. 1992. "Voters as Fiscal Conservatives", Quarterly Journal of Economics 107(2): 327.

Stevenson, Randolph T. 2001. "The Economy and Policy Mood: A Fundamental Dynamic of Democratic Politics?", American Journal of Political Science 45(3): 620-633. 